\title{
THE ANALYSIS AND INTERPRETATION OF DIFFERENCES BETWEEN RECIPROCAL CROSSES OF NICOTIANA RUSTICA VARIETIES
}

\author{
J. L. JINKS, JEAN M. PERKINS and S. R. GREGORY* \\ Departments of Genetics, University of Birmingham, Birmingham B15 2TT
}

Received 15.ix.71

\section{INTRODUCTION}

THERE are two kinds of differences between reciprocal crosses once sexlinkage and preferential segregation have been ruled out by appropriate breeding tests. These are transient and persistent maternal (or paternal) effects. Differences in the maternal environment can give rise to transient reciprocal differences. Such differences are known in the animal kingdom where they have been traced to differences in the maternal genotypes (see, for example, Barnes, 1968; Fulker, 1970; Mather and Jinks, 1971). Persistent reciprocal differences usually arise through unequal contributions of cytoplasmic determinants from the female and male gametes to the zygote. Such differences are prevalent in the plant kingdom. They often resemble differences at a single gene locus since only a single major function is affected (see Jinks, 1964, for a review).

A more unusual kind of reciprocal difference found in Nicotiana rustica is reported in this paper. The difference while transient persists over three generations; it affects only metrical characters such as final height and flowering time which are continuously varying characters in this material and its magnitude is environmentally dependent. While it has many similarities to recently reported examples of maternally inherited differences in clonally reproducing plants (Beddows, Breese and Lewis, 1962; Hayward and Breese, 1968) and in maize (Garwood, Weber, Lambert and Alexander, 1970; Bhat and Dhawan, 1971) its inheritance has a number of unique features.

\section{DETEGTION OF REGIPROGAL DIFFERENGES}

The data are taken from generations obtained by crossing long inbred varieties 2 and 12 of $\mathcal{N}$. rustica grown in each of 18 environments consisting of one or more independent experiments (sowings) in each of nine years. All of the $F_{1}$ and some of the generations derived from it by selfing, sibmating and back-crossing are available as reciprocal families. Two characters have been recorded, flowering time (in days after an arbitary date) and final height (in centimetres from 1968 onwards and conversions to this scale from inches for earlier years). For each character the differences between the means of the reciprocal $F_{1}$ families $(12 q \times 2 \hat{\sigma}-2 q \times 12 \hat{\jmath})$, the standard errors of these differences and their significances are given in table 1. For flowering time 12 of the 18 differences between the means of reciprocal

* Present address: Plant Breeding Institute, Trumpington, Cambridge. 
crosses are significant $(\mathrm{P} ₹ 0 \cdot 05)$ and 11 of these significant differences are positive $\left(12 \% \times 2 \delta^{\wedge}>20 \times 12 \hat{\jmath}\right)$. For final height, 11 are significant and 9 are again positive. An analysis of variance of the differences between the reciprocal crosses shows that they vary significantly in magnitude over the 18 environments $(P<0.001$ for both characters). That is, they interact with the environments.

TABLE 1

Differences between the family means, their standard errors and significances for the flowering times and final heights of the two reciprocal $F_{1}$ s obtained from crosses between inbred varieties 2 and 12 of Nicotiana rustica when grown in 18 environments

\begin{tabular}{|c|c|c|c|c|c|c|c|c|c|c|}
\hline \multirow[b]{2}{*}{ Environment } & \multirow[b]{2}{*}{ Year } & \multirow[b]{2}{*}{ Sowing } & \multicolumn{4}{|c|}{ Flowering time } & \multicolumn{4}{|c|}{ Final height } \\
\hline & & & $\begin{array}{r}F_{1}(12 \times 2) \\
-F_{1}(2 \times 12)\end{array}$ & S.E. & d.f. & $\mathbf{P}$ & $\begin{array}{r}F_{1}(12 \times 2) \\
-F_{1}(2 \times 12)\end{array}$ & S.E. & d.f. & $\mathbf{P}$ \\
\hline 1 & 1951 & & -1.3 & $2 \cdot 75$ & 16 & n.s. & $-1 \cdot 0$ & $3 \cdot 20$ & 16 & n.s. \\
\hline 2 & 1952 & & $5 \cdot 1$ & $2 \cdot 19$ & 16 & * & -13.9 & $6 \cdot 10$ & 16 & * \\
\hline 3 & 1953 & & $-10 \cdot 2$ & 1.96 & 16 & $* * *$ & $-12 \cdot 9$ & $4 \cdot 60$ & 16 & $* *$ \\
\hline 4 & 1955 & & 1.7 & $1 \cdot 14$ & 16 & n.s. & $2 \cdot 9$ & 6.73 & 16 & n.s. \\
\hline 5 & 1956 & & $9 \cdot 0$ & $4 \cdot 10$ & 24 & * & $21 \cdot 6$ & $8 \cdot 58$ & 23 & * \\
\hline 6 & 1967 & & $2 \cdot 9$ & 3.01 & 32 & n.s. & $30 \cdot 2$ & $6 \cdot 24$ & 32 & $* * *$ \\
\hline 7 & 1968 & 1 & $15 \cdot 9$ & $3 \cdot 22$ & 18 & $* * *$ & $4 \cdot 2$ & 3.74 & 18 & n.s. \\
\hline 8 & & 2 & $2 \cdot 2$ & 3.06 & 18 & n.s. & $14 \cdot 3$ & $5 \cdot 51$ & 18 & * \\
\hline 9 & & 3 & $5 \cdot 2$ & $2 \cdot 18$ & 18 & * & $17 \cdot 3$ & $6 \cdot 58$ & 18 & * \\
\hline 10 & & 4 & 0.6 & $2 \cdot 39$ & 18 & n.s. & $7 \cdot 6$ & $2 \cdot 74$ & 18 & * \\
\hline 11 & & 5 & $9 \cdot 7$ & $1 \cdot 81$ & 18 & *** & $9 \cdot 4$ & $3 \cdot 39$ & 18 & * \\
\hline 12 & & 6 & $9 \cdot 2$ & 3.04 & 17 & ** & $14 \cdot 1$ & $6 \cdot 88$ & 17 & $\dagger$ \\
\hline 13 & & 7 & $9 \cdot 5$ & $3 \cdot 24$ & 18 & ** & $14 \cdot 2$ & $4 \cdot 50$ & 18 & $* *$ \\
\hline 14 & 1969 & 1 & 1.3 & 0.36 & 196 & **** & -0.4 & 1.49 & 195 & n.s. \\
\hline 15 & & 2 & $5 \cdot 0$ & 0.75 & 196 & $* * *$ & $9 \cdot 7$ & $2 \cdot 23$ & 196 & $* * *$ \\
\hline 16 & 1970 & 1 & -0.5 & 1.53 & 36 & n.s. & $-4 \cdot 3$ & $4 \cdot 39$ & 36 & n.s. \\
\hline 17 & & 2 & $4 \cdot 9$ & $1 \cdot 30$ & 56 & *** & $2 \cdot 2$ & 3.74 & 56 & n.s. \\
\hline 18 & & 3 & 1.9 & 0.87 & 36 & $*$ & -4.0 & $2 \cdot 45$ & 36 & n.s. \\
\hline
\end{tabular}

n.s. Probability is non-significant.

$\dagger$ Probability $=0.05$.

* Probability $=0.01-0.05 ; * *$ Probability $=0.001-0.01 ; * * *$ Probability $=0.001$.

In table 2 the magnitude and sign of the reciprocal difference in each environment is compared with the magnitude and sign of the corresponding difference between the parental varieties $(12-2)$. Two values of the latter are given for each reciprocal difference. These are the parental difference for the environment in which the $F_{1}$ families were grown and for the environment in which the $F_{1}$ crosses were made. While the two estimates of the parental difference, corresponding with each difference between reciprocal $F_{1}$ families, often differ in magnitude they agree in sign except for one character in one environment (final height, environment 1). If the difference between reciprocal crosses results from each family resembling its maternal more than its paternal parent, it should have the same sign as the difference between its parents. This is so for final height in the majority of environments but it is not so for flowering time (table 2). Thus in most environments there is a maternal effect on final height but what appears to be a paternal effect on flowering time. 
TABLE 2

Differences between reciprocal $F_{1}$ crosses for flowering time and final height taken from table 1 compared with the corresponding differences between their parental varieties $(P 12-P 2)$ for the same environment in which the $F_{1}$ cross was made $(I)$ and for the environment in which the $F_{1}$ cross was grown $(I I)$

\begin{tabular}{|c|c|c|c|c|c|c|c|c|}
\hline \multirow[b]{2}{*}{ Environment } & \multirow[b]{2}{*}{ Year } & \multirow[b]{2}{*}{ Sowing } & \multicolumn{3}{|c|}{ Flowering time } & \multicolumn{3}{|c|}{ Final height } \\
\hline & & & $\begin{array}{r}F_{1}(12 \times 2) \\
-F_{1}(2 \times 12)\end{array}$ & $\frac{\mathrm{P} 12-\mathrm{P} 2}{\mathrm{I}}$ & $\underset{\text { II }}{\mathrm{P} 12-\mathrm{P} 2}$ & $\begin{array}{r}F_{1}(12 \times 2) \\
-F_{1}(2 \times 12)\end{array}$ & $\underset{I}{P 12-P 2}$ & $\begin{array}{c}\mathrm{P} 12-\mathrm{P} 2 \\
\text { II }\end{array}$ \\
\hline 1 & 51 & & $-1 \cdot 3$ & $-11 \cdot 8$ & $-4 \cdot 8$ & -1.0 & $-3 \cdot 0$ & $36 \cdot 6$ \\
\hline 2 & 52 & & $5 \cdot 1$ & -4.8 & -0.7 & $-13 \cdot 9$ & $36 \cdot 6$ & $45 \cdot 2$ \\
\hline 3 & 53 & & $-10 \cdot 2$ & -0.7 & $-10 \cdot 3$ & $-12 \cdot 9$ & $45 \cdot 2$ & $40 \cdot 0$ \\
\hline 4 & 55 & & 1.7 & * & $-6 \cdot 0$ & $2 \cdot 9$ & $*$ & $54 \cdot 5$ \\
\hline 5 & 56 & & $9 \cdot 0$ & $-6 \cdot 0$ & $-14 \cdot 7$ & $21 \cdot 6$ & $54 \cdot 5$ & $22 \cdot 4$ \\
\hline 6 & 57 & & $2 \cdot 9$ & $-14 \cdot 7$ & $-7 \cdot 6$ & $30 \cdot 2$ & $22 \cdot 4$ & $28 \cdot 4$ \\
\hline 7 & 68 & 1 & $15 \cdot 9$ & $-7 \cdot 6$ & $-21 \cdot 0$ & $4 \cdot 2$ & $16 \cdot 1$ & 29.9 \\
\hline 8 & & 2 & $2 \cdot 2$ & $-22 \cdot 1$ & $-16 \cdot 6$ & $14 \cdot 3$ & $16 \cdot 1$ & $48 \cdot 8$ \\
\hline 9 & & 3 & $5 \cdot 2$ & $-22 \cdot 1$ & $-11 \cdot 8$ & $17 \cdot 3$ & $16 \cdot 1$ & $35 \cdot 1$ \\
\hline 10 & & 4 & $0 \cdot 6$ & $-22 \cdot 1$ & $-12 \cdot 6$ & $7 \cdot 6$ & $16 \cdot 1$ & $47 \cdot 6$ \\
\hline 11 & & 5 & $9 \cdot 7$ & $-22 \cdot 1$ & $-22 \cdot 6$ & $9 \cdot 4$ & $16 \cdot 1$ & $30 \cdot 1$ \\
\hline 12 & & 6 & $9 \cdot 2$ & $-22 \cdot 1$ & $-11 \cdot 0$ & $14 \cdot 1$ & $16 \cdot 1$ & $43 \cdot 2$ \\
\hline 13 & & 7 & $9 \cdot 5$ & $-22 \cdot 1$ & $-7 \cdot 5$ & $14 \cdot 2$ & $16 \cdot 1$ & $41 \cdot 6$ \\
\hline 14 & 69 & 1 & 1.3 & -18.5 & $-16 \cdot 8$ & -0.4 & $48 \cdot 6$ & $36 \cdot 9$ \\
\hline 15 & & 2 & 5.0 & $-18 \cdot 5$ & $-26 \cdot 5$ & $9 \cdot 7$ & $48 \cdot 6$ & $38 \cdot 4$ \\
\hline 16 & 70 & 1 & -0.5 & $-39 \cdot 2$ & -0.7 & $-4 \cdot 3$ & $37 \cdot 1$ & $32 \cdot 0$ \\
\hline 17 & & 2 & 4.9 & $-39 \cdot 2$ & -25.2 & $2 \cdot 2$ & $37 \cdot 1$ & $25 \cdot 4$ \\
\hline 18 & & 3 & 1.9 & $-39 \cdot 2$ & $-16 \cdot 4$ & $-4 \cdot 0$ & $37 \cdot 1$ & $29 \cdot 9$ \\
\hline
\end{tabular}

* Parental scores not known for the environment in which these $F_{1}$ reciprocal crosses were made.

\section{Further generations}

Further generations derived from the reciprocal $F_{1}$ families by selfing, sib-mating and back-crossing are available for all environments except 1951 and the seven sowings in 1968. In 1955, 1957 and sowings 1 and 3 in 1970 the further generations are confined to reciprocal $F_{2}$ families and in 1952 and 1953 to these and the reciprocal first back-crosses. For the remaining four environments, namely 1956, sowings 1 and 2 in 1969 and sowing 2 in 1970 there is an extensive range of additional generations many of which are available reciprocally (table 3 ). We can, therefore, pursue the detection and analysis of the reciprocal differences found in the $F_{1}$ in a number of directions.

(i) The further generations which have been identically bred from the reciprocal $F_{1}$ families can be examined for evidence of the persistence of the difference found between the reciprocal $F_{1}$ families.

(ii) The other generations which have been made reciprocally can be examined for differences between the reciprocal families.

(iii) Models of the expected means of the further generations can be derived assuming the presence and absence of maternal or paternal inheritance and assuming that the difference between the reciprocal crosses persists or do not persist in the grandprogeny and great-grandprogeny, etc. Examination of the models will then provide tests of these assumptions and the model fitting, estimates of the components of the means. 


\section{(i) Persistence of the reciprocal difference}

The signs and significances of the differences between families which have been identically bred from the different reciprocal $F_{1}$ families are given for final height and flowering time in tables 3 and 4, respectively.

TABLE 3

Tests of significance of the differences in final height between families of the same generation but derived from different reciprocal $F_{1}$ families. The sign of the difference and its significance are given (symbols as for table 1)

\begin{tabular}{|c|c|c|c|c|c|c|c|c|c|}
\hline \multirow[b]{2}{*}{ Environment } & & \multicolumn{8}{|c|}{ Generation } \\
\hline & & $\mathbf{F}_{2}$ & $\mathbf{B}_{1}$ & $\mathbf{B}_{2}$ & $F_{3}$ & $F_{2} \times P_{12}$ & $\mathrm{~F}_{2} \times \mathrm{P}_{2}$ & $F_{2} \times F_{1}$ & $F_{2}$ bip \\
\hline 1952 & & - n.s. & $t^{* *}$ & +n.s. & - & - & - & - & - \\
\hline 1953 & & +n.s. & - n.s. & +n.s. & - & - & - & - & - \\
\hline 1955 & & - n.s. & - & - & - & - & - & - & - \\
\hline 1956 & & +n.s. & 一 & - & + n.s. & +n.s. & - n.s. & +n.s. & - \\
\hline 1959 & & - n.s. & - & - & - & - & - & - & - \\
\hline 1969 & 1 & - n.s. & - & - & $+* * *$ & $+^{*}$ & $+^{* *}$ & +n.s. & - \\
\hline & 2 & - n.s. & - & - & $+*$ & $+* *$ & + n.s. & $+* *$ & - \\
\hline 1970 & 1 & - n.s. & - & - & - & - & - & - & - \\
\hline & 2 & - n.s. & - & - & +n.s. & $+* *$ & +n.s. & -n.s. & +n.s. \\
\hline & 3 & +n.s. & - & - & - & - & - & - & - \\
\hline
\end{tabular}

TABLE 4

Tests of significance of the differences in flowering time between families of the same generation but derived from different reciprocal $F_{1}$ families. The sign of the difference and its significance are given (symbols as for table 1)

\begin{tabular}{|c|c|c|c|c|c|c|c|c|c|}
\hline \multirow{2}{*}{\multicolumn{2}{|c|}{ Environment }} & \multicolumn{8}{|c|}{ Generation } \\
\hline & & $F_{2}$ & $B_{1}$ & $\mathrm{~B}_{2}$ & $F_{3}$ & $F_{2} \times P_{12}$ & $F_{2} \times P_{2}$ & $F_{2} \times F_{1}$ & $\mathrm{~F}_{2}$ bip \\
\hline 1952 & & -n.s. & +n.s. & 0n.s. & - & - & - & - & - \\
\hline 1953 & & +n.s. & -n.s. & -n.s. & - & - & - & - & - \\
\hline 1955 & & $t^{*}$ & - & - & - & - & - & 一 & - \\
\hline 1956 & & +n.s. & - & 一 & On.s. & -n.s. & - n.s. & -n.s. & - \\
\hline 1957 & & +n.s. & - & - & - & - & - & - & - \\
\hline 1969 & 1 & -n.s. & - & - & $+* * *$ & + n.s. & + n.s. & -n.s. & - \\
\hline & 2 & +n.s. & - & - & $+^{* *}$ & $+*$ & - n.s. & -n.s. & - \\
\hline 1970 & 1 & $-*$ & - & - & - & - & - & - & - \\
\hline & 2 & - n.s. & 一 & - & $+^{*}$ & $+* *$ & $+* * *$ & -n.s. & + n.s. \\
\hline & 3 & +n.s. & - & - & - & - & - & - & - \\
\hline
\end{tabular}

For each character there are 31 such differences available over the various generations and environments. For final height eight of these differences, all positive, are significant $(\mathrm{P}<0 \cdot 05)$ while for the flowering time the same number are significant but one is negative. Thus of the 16 significant differences detectable in later generations 15 have the same sign as the original difference between the $\mathrm{F}_{1}$ reciprocal crosses. For both characters there is, therefore, evidence of the persistence of the difference found between the $\mathrm{F}_{1}$ reciprocal crosses for up to two further generations, i.e. to generations of which the original parents of the $F_{1}$ reciprocal families are the greatgrandparents.

To determine the degree of persistence we can compare the mean magnitude of the differences between reciprocal crosses for generations in which 
the inbred varieties (2 and 12) are parents, grandparents and greatgrandparents. Because of the interaction of the reciprocal differences with the environment (table 1 and section 2) and because not all generations were raised in all environments we must restrict these comparisons to environments in which the relevant generations were grown together. For 1956, 1969 sowings 1 and 2 and 1970 sowing 2, we have a complete set of five further generations in addition to the $F_{1}$. These six generations fall into three groups in which the inbred varieties are the parents $\left(F_{1}\right.$ families), the grandparents $\left(F_{2}\right.$ families) and the great-grandparents $\left(F_{3}, F_{2} \times P_{12}\right.$, $\mathrm{F}_{2} \times \mathrm{P}_{2}$ and $\mathrm{F}_{2} \times \mathrm{F}_{1}$ families) respectively. The mean difference between reciprocal crosses and their standard errors for each of these three groups for each character are given in table 5. It is quite clear from table 5 that

TABLE 5

The mean difference between reciprocal $F_{1}$ families and families derived from them for which the inbred varieties are grandparents and great-grandparents, respectively, in 1956, 1969 sowings 1 and 2 and 1970 sowing 2, for final height and flowering time (symbols as for table 1)

$\begin{array}{lccc} & \begin{array}{c}\text { Inbred varieties } \\ \text { parents }\end{array} & \begin{array}{c}\text { Inbred varieties } \\ \text { grandparents }\end{array} & \begin{array}{c}\text { Inbred varieties } \\ \text { great-grandparents }\end{array} \\ \text { Final height } & 8 \cdot 38 \pm 2 \cdot 46 * & -0.61 \pm 3.01 \mathrm{n} . \mathrm{s} . & 3 \cdot 26 \pm 0.41 * * * \\ \text { Flowering time } & 5.05 \pm 1.57 * & 1.58 \pm 2.80 \mathrm{n} . \mathrm{s.} & 0.84 \pm 0.22 * *\end{array}$

while we can still detect differences between families derived from different reciprocal $F_{1}$ families, the magnitude of these differences are on average relatively small compared with those in the $F_{1}$. For example, for flowering time only 31 per cent. of the difference on average persists to the grandprogeny and 17 per cent. to the great-grandprogeny, while for final height the level of persistence is higher in the great-grandprogeny but is zero, if not negative, in the grandprogeny. Thus the difference between reciprocal $\mathrm{F}_{1}$ families diminishes in the generations derived from them, i.e. it is transient.

\section{(ii) Differences between reciprocal crosses in other generations}

Only one of the generations derived from the reciprocal $F_{1}$ families, namely $\mathrm{B}_{2}$, was itself made reciprocally $\left(\mathrm{F}_{1}\right.$ 우 $\times \mathrm{P}_{2} \mathrm{O}^{\wedge}$ and $\mathrm{P}_{2}$ 우 $\left.\times \mathrm{F}_{1} \mathrm{o}^{\lambda}\right)$ and then in one season, 1956, only. For neither final height nor flowering time is there a significant difference between these reciprocal $B_{2}$ families. Since, however, only one difference between reciprocal crosses out of the six comparisons available in this season was significant, this single test is hardly conclusive.

\section{(iii) Models and tests}

In the second sowing in 1970 all the 26 families listed in table 6 are available and in 1956 and sowings 1 and 2 of 1969 the first 16 families are available plus an additional reciprocal $B_{2}$ family in 1956 (see section 3 (ii)). For these three sets of data we have sufficient information to test the adequacy of alternative models for the determination of the family means, including the differences between the means of reciprocal pairs of families, and to test the assumptions underlying these models.

Any adequate model must specify the contribution of the progeny genotype to the family means as well as that of the maternal or paternal parent. 
喜 $|1||||||+\infty| 1|-\cdots+\infty| 1-\infty \mid+$ 意 ||||$--||+\infty|1| \mid+\infty+\infty)$

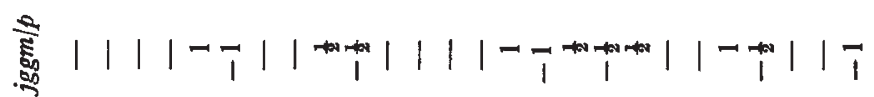

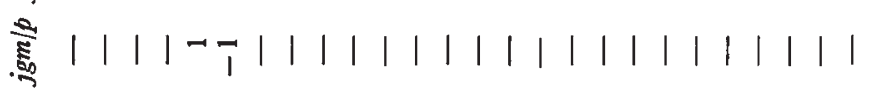

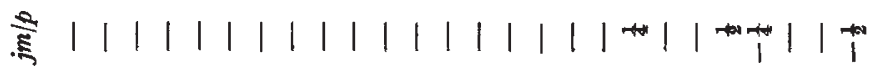

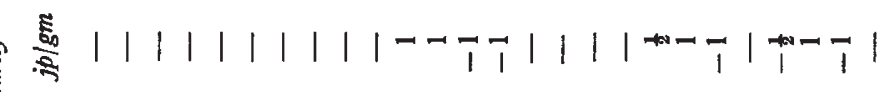

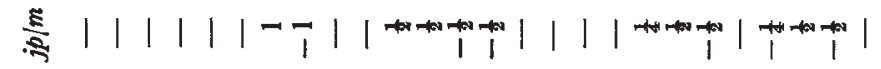
营

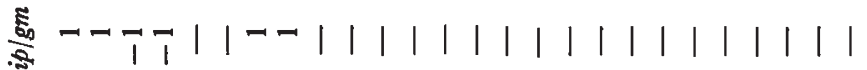
蛋-

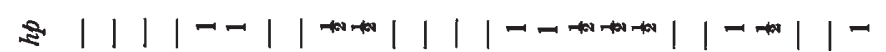

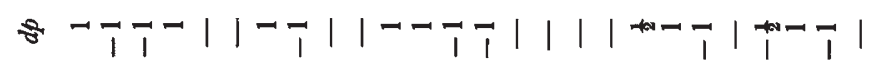
䔍

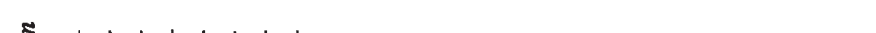

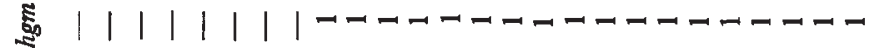

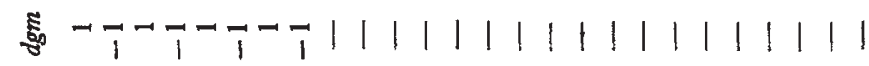
ฐ

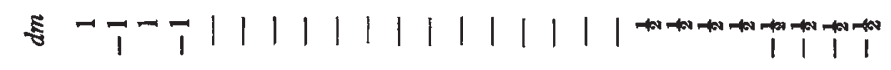
บ N $N$ N

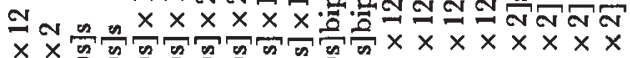

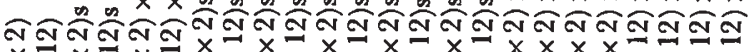

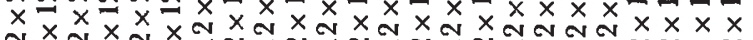

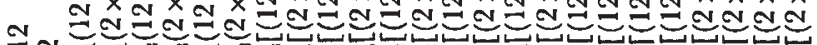

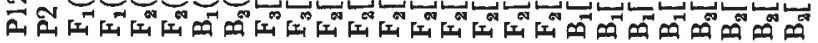
- 
Previous investigations of this cross, which have been solely concerned with the contribution of the progeny genotype, show that the control of both characters is complex, including additive and dominance gene action and epistatic interaction (Jinks, 1956; Jinks and Jones, 1958; Jinks and Perkins, 1970). The specification of the progeny genotypic contribution must, therefore, include these effects. Since no test for linkage between interacting genes was available in these earlier experiments, this possibility must also be examined. Expectation for the means of the 26 kinds of families available in the present data which include interactions between two and three loci at a time and for linkage between pairs of such loci have been described along with tests for detecting their presence (Jinks and Perkins, 1969).

A specification of maternal effects which assume that they arise from the additive and dominance action of genes of the maternal genotype and analyses which provide tests of this assumption have been described by Barnes (1968), Fulker (1970), Mather and Jinks (1971) and Hay (1972). A general model which would allow for persistence over two or more generations would need to specify in addition:

(i) epistatic effects of the maternal genotype;

(ii) persistence of the maternal effect at any level over any number of generations, i.e. maternal line effects;

(iii) interaction between progeny genotype and maternal effect;

(iv) the corresponding items for a paternal effect arising from the action and interaction of genes of the paternal genotype;

(v) interaction between the maternal and paternal effects.

The specification of items (i) and (iii) have been discussed by Mather and Jinks (1971).

Because the simple additive-dominance model of maternal effects was inadequate for the present data, expectations have been derived and fitted to these data which include all five additional sources of variation. Their complexity rules out a full description here. We shall, therefore, confine our presentation to those sources of variation which were necessary to arrive at the simplest, adequate model, namely items (ii), (iv) and (v).

Expectations which include these effects are given in table 6 for all available kinds of families. Seventeen parameters are required. Five, $d m$, $d g m, d g g m, h m$ and $h g m$ specify the additive $(d)$ and dominance $(h)$ maternal (m) grandmaternal $(\mathrm{gm})$ and great-grandmaternal ( $\mathrm{ggm}$ ) contributions, while two $d p$ and $h p$ are corresponding paternal $(p)$ contributions. The ten remaining are all the interactions between maternal line and paternal effects that could arise among these 26 kinds of family. By analogy with the specification of the interactions among non-allelic genes in the progeny genotype we have used $i$ to symbolise the interaction between an additive maternal line effect and an additive paternal effect; $j$ for the interaction between an additive effect of one parent and a dominance effect of the other and $l$ for the interaction between a dominance maternal line effect and a dominance paternal effect.

On the basis of these expectations a number of tests have been devised (table 7). These tests are expected to be non-significant in the absence of one or more of the effects specified. If significant, one or more of these effects are present. For example, the first set of four tests in table 7 are expected to be non-significant in the absence of maternal, grandmaternal 
TABLE 7

Tests of the likeliest causes of failure of a simple additive-dominance model of the family means in the N. rustica data

Likeliest causes of significance

Test

1. Maternal line effects
(a) $[d g m]$
(b) $[$ dggm $]$
(c) $[h m]+\frac{3}{2}[l m]-2[h g m]$
(d) $[h m]+\frac{8}{2}[l m]-2[h g m]$

$$
\begin{aligned}
& \frac{1}{2} \mathrm{~F}_{2}[(12 \times 2) \mathrm{s}]+\left[\frac{1}{2} \mathrm{~F}_{2}[(2 \times 12) \mathrm{s}] \times \mathrm{F}_{1}(2 \times 12)\right]-\frac{1}{2} \mathrm{~F}_{2}[(2 \times 12) \mathrm{s}] \\
& -\left[\frac{1}{2} \mathrm{~F}_{2}[(12 \times 2) \mathrm{s}] \times \mathrm{F}_{1}(12 \times 2)\right]=0 \\
& {\left[\frac{1}{4} \mathrm{~F}_{2}[(12 \times 2) \mathrm{s}] \times 12\right]+\left[\frac{1}{4} \mathrm{~F}_{2}[(12 \times 2) \mathrm{s}] \times 2\right]-\left[\frac{1}{4} \mathrm{~F}_{2}[(2 \times 12) \mathrm{s}]\right.} \\
& \times 12]-\left[\frac{1}{4} \mathrm{~F}_{2}[(2 \times 12) \mathrm{s}] \times 2\right]=0 \\
& \mathrm{~F}_{2}[(12 \times 2) \mathrm{s}]+\mathrm{F}_{2}[(2 \times 12) \mathrm{s}]-\left[\mathrm{F}_{2}[(12 \times 2) \mathrm{s}] \times \mathrm{F}_{1}(12 \times 2)\right] \\
& -\left[\mathrm{F}_{2}[(2 \times 12) \mathrm{s}] \mathrm{F}_{1}(2 \times 12)\right]=0 \\
& \frac{1}{2} \mathrm{~B}_{1}[(12 \times 2) \times 12]+\frac{1}{2} \mathrm{~B}_{2}[(2 \times 12) \times 2]+\frac{1}{2} \mathrm{~F}_{2}[(12 \times 2) \mathrm{s}] \\
& +\frac{1}{2} \mathrm{~F}_{2}[(2 \times 12) \mathrm{s}]-\left[\frac{1}{4} \mathrm{~F}_{2}[(12 \times 2) \mathrm{s}] \times 12\right]-\left[12 \mathrm{~F}_{2}[(2 \times 12) \mathrm{s} \times 12]\right. \\
& -\left[\frac{1}{4} \mathrm{~F}_{2}[(12 \times 2) \mathrm{s}] \times 2\right]-\left[\frac{1}{4} \mathrm{~F}_{2}[(2 \times 12) \mathrm{s}] \times 2\right]-\left[\frac{1}{2} \mathrm{~F}_{2}(12 \times 2) \mathrm{s}\right] \\
& \left.\times \mathrm{F}_{1}(12 \times 2)\right]-\left[\frac{1}{2} \mathrm{~F}_{2}[(2 \times 12) \mathrm{s}] \times \mathrm{F}_{1}(2 \times 12)\right]=0
\end{aligned}
$$

2. Paternal effects and linkage of pairs of interacting genes
(a) $[h p]+\frac{3}{2}[l p]$ and
$\frac{1}{4}[p i]-\left[p^{2} i\right]+\left[p^{3} i\right]+1[p l]-4\left[p^{2} l\right]$
$\left[F_{2}[(12 \times 2) s] \times F_{1}(12 \times 2)\right]+\left[F_{2}[(2 \times 12) s] \times F_{1}(2 \times 12)\right]$
$+\frac{9}{2}\left[p^{3} l\right]-3\left[p^{4} l\right]+3\left[p^{5} l\right]-\left[p^{b l}\right]^{*}$
$-\left[\mathrm{F}_{2}[(12 \times 2) \mathrm{s}] \mathrm{bip}\right]-\left[\mathrm{F}_{2}[(2 \times 12) \mathrm{s}] \mathrm{bip}\right]=0$

3. Non-allelic interactions (trigenic) in

progeny genotype
(a) $\frac{3}{18}[i a b c]+\frac{8}{16}[j a / b c]$
(b) $\frac{3}{16}[i a b c]$

$$
\begin{aligned}
& \frac{1}{2} P_{1}(12)-\frac{1}{2} P_{2}(2)-B_{11}[[(12 \times 2) \times 12] \times 12]-B_{12}[[(12 \times 2) \\
& \times 12] \times 2]+B_{21}[[(2 \times 12) \times 2] \times 12]+B_{22}[[(2 \times 12) \times 2] \times 2]=0 \\
& B_{1}[(12 \times 2) \times 12]-B_{2}[(2 \times 12) \times 2]-2\left[B_{1}[(12 \times 2) \times 12]\right. \\
& \left.\times F_{1}(12 \times 2)\right]+2\left[B_{2}[(2 \times 12) \times 2] \times F_{1}(2 \times 12)\right]=0
\end{aligned}
$$

4. Non-allelic interactions (trigenic) in progeny genotype and maternal line $x$ paternal interactions
(a) $\frac{3}{16}[j a b / c]+\frac{8}{16}[l a b c]$ and
$-2[i p / m]-[i p / g g m]$

$$
\begin{aligned}
& \frac{1}{2} F_{1}(12 \times 2)+\frac{1}{2} F_{1}(2 \times 12)-\frac{1}{2} P_{1}(12)-\frac{1}{2} P_{2}(2)+B_{11}[[(12 \times 2) \\
& \times 12] \times 12]-B_{12}[[(12 \times 2) \times 12] \times 2]-B_{21}[[(2 \times 12) \times 2] \times 12] \\
& +B_{22}[[(2 \times 12) \times 2] \times 2]=0
\end{aligned}
$$

5. Maternal line effect $\times$ progeny genotype interaction and maternal line $\times$ paternal interaction
(a) $[$ d.dggm] and 2[ip/ggm $]$
(b) $\frac{1}{2}[d . h m]+\frac{1}{2}[h . d m]-[d . h g m]$ and $[j p / m]-2[j p / g m]-2[j g m / p]$ $-2[j g g m / p]$
(c) $[h . d g g m]$ and $-[j g g m / p]$
(d) $[h . d g g m]$ and $-[$ jggm/p]

$$
\begin{aligned}
& \frac{1}{2}\left[\mathrm{~F}_{2}[(12 \times 2) \mathrm{s}] \times 12\right]-\frac{1}{2}\left[\mathrm{~F}_{2}[(12 \times 2) \mathrm{s}] \times 2\right]-\frac{1}{2}\left[\mathrm{~F}_{2}(2 \times 12) \mathrm{s}\right] \\
& \times 12]+\frac{1}{2}\left[\mathrm{~F}_{2}[(2 \times 12) \mathrm{s}] \times 2\right]=0 \\
& \mathrm{~B}_{1}[(12 \times 2) \times 12]-\mathrm{B}_{2}[(2 \times 12) \times 2]-\mathrm{F}_{2}[(12 \times 2) \mathrm{s}]+\mathrm{F}_{2}[(2 \times 12) \mathrm{s}] \\
& -\frac{1}{2}\left[\mathrm{~F}_{2}[(12 \times 2) \mathrm{s}] \times 12\right]+\frac{1}{2}\left[\mathrm{~F}_{2}[(12 \times 2) \mathrm{s}] \times 2\right]-\left[\mathrm{F}_{2}[(2 \times 12) \mathrm{s}]\right. \\
& \times 12]+\frac{1}{2}\left[\mathrm{~F}_{2}[(2 \times 12) \mathrm{s}] \times 2\right]=0 \\
& 2\left[\mathrm{~F}_{2}[(12 \times 2) \mathrm{s}] \times \mathrm{F}_{1}(12 \times 2)\right]-2\left[\mathrm{~F}_{2}[(2 \times 12) \mathrm{s}] \times \mathrm{F}_{1}(2 \times 12)\right] \\
& -2 \mathrm{~F}_{3}[(12 \times 2) \mathrm{s}] \mathrm{s}+2 \mathrm{~F}_{3}[(2 \times 12) \mathrm{s}] \mathrm{s}=0 \\
& {\left[\mathrm{~F}_{2}[(12 \times 2) \mathrm{s}] \times \mathrm{F}_{1}(12 \times 2)\right]-\left[\mathrm{F}_{2}[(2 \times 12) \mathrm{s}] \times \mathrm{F}_{1}(12 \times 2)\right]} \\
& +\left[\mathrm{F}_{2}[(12 \times 2) \mathrm{s}] \mathrm{bip}\right]-\left[\mathrm{F}_{2}[(2 \times 12) \mathrm{s}] \mathrm{bip}\right]-2 \mathrm{~F}_{3}[(12 \times 2) \mathrm{s}] \mathrm{s} \\
& +2 \mathrm{~F}_{3}[(2 \times 12) \mathrm{s}] \mathrm{s}=0
\end{aligned}
$$

* $p$ used as a coefficient is the recombination frequency, elsewhere it symbolises a paternal effect.

and great-grandmaternal effects. The likeliest cause of significance in the present data are indicated alongside the tests. But significance could arise from more complex maternal, grandmaternal and great-grandmaternal contributions including interactions of these with the progeny genotype. Nevertheless, by examining the pattern of significances over all the tests it is possible to arrive at a minimal set of causes. 
The results of applying these tests to the final height and flowering time data of 1956, 1969 sowings 1 and 2 and 1970 sowing 2 are summarised in tables 8 and 9 respectively. None of the tests applicable to 1956 is significant.

TABLE 8

The results of applying the tests in table 7 to the final height data (jymbols as in table 1)

\begin{tabular}{|c|c|c|c|c|}
\hline Test & 1956 & 1969 sowing 1 & 1969 sowing 2 & 1970 sowing 2 \\
\hline $\begin{array}{r}1 a \\
b\end{array}$ & $\begin{array}{l}4 \cdot 04 \pm 5 \cdot 00 \text { n.s. } \\
0 \cdot 75 \pm 2 \cdot 11 \text { n.s. }\end{array}$ & $\begin{array}{r}-1.58 \pm 1.52 \text { n.s. } \\
2.79 \pm 0.73^{* * *}\end{array}$ & $\begin{array}{c}-5 \cdot 48 \pm 1 \cdot 78^{* *} \\
2 \cdot 15 \pm 0.96^{*}\end{array}$ & $\begin{array}{r}-1.63 \pm 2.02 \text { n.s. } \\
1.35 \pm 0.94 \text { n.s. }\end{array}$ \\
\hline$c$ & $10.45 \pm 10.01$ n.s. & - & - & - \\
\hline$d$ & - & $2 \cdot 12 \pm 1.90$ n.s. & $0.74 \pm 2.27$ n.s. & $1 \cdot 13 \pm 2.48$ n.s. \\
\hline $2 a$ & - & - & - & $-5.23 \pm 3.03$ n.s. \\
\hline $3 a$ & - & - & - & $4.25 \pm 2.81$ n.s. \\
\hline$b$ & - & - & - & $-4 \cdot 70 \pm 5 \cdot 22$ n.s. \\
\hline $4 a$ & - & - & - & $10 \cdot 36 \pm 3 \cdot 38 * *$ \\
\hline $\begin{array}{r}5 a \\
b\end{array}$ & $2 \cdot 90 \pm 4 \cdot 22$ n.s. & $\begin{array}{r}-2.74 \pm 1.46 \text { n.s. } \\
5.11 \pm 3.11 \text { n.s. }\end{array}$ & $\begin{array}{r}0.44 \pm 1.91 \text { n.s. } \\
-6.05 \pm 3.86 \text { n.s. }\end{array}$ & $\begin{array}{r}2.58 \pm 1.88 \text { n.s. } \\
-6.21 \pm 4 \cdot 16 \text { n.s. }\end{array}$ \\
\hline$c$ & $-0.64 \pm 19.57$ n.s. & $-13 \cdot 27 \pm 6 \cdot 47^{*}$ & $-1.82 \pm 8.05$ n.s. & $-2.72+5.33$ n.s. \\
\hline
\end{tabular}

TABLE 9

The results of applying the tests in table 7 to the flowering time data (symbols as in table 1)

\begin{tabular}{|c|c|c|c|c|}
\hline Test & 1956 & 1969 sowing 1 & 1969 sowing 2 & 1970 sowing 2 \\
\hline $\begin{array}{r}1 a \\
b \\
c\end{array}$ & $\begin{array}{r}4.97 \pm 3.21 \text { n.s. } \\
-0.06 \pm 0.85 \text { n.s. } \\
9.67+6.43 \text { n.s. }\end{array}$ & $\begin{array}{c}-0.25 \pm 0.45 \text { n.s. } \\
0.18 \pm 0.23 \text { n.s. }\end{array}$ & $\begin{array}{l}1.00 \pm 0.66 \text { n.s. } \\
0.18 \pm 0.41 \text { n.s. }\end{array}$ & $\begin{array}{c}-1 \cdot 10 \pm 0.67 \text { n.s. } \\
1 \cdot 42 \pm 0 \cdot 29 * * * \\
-\end{array}$ \\
\hline$d$ & - & $-1.87 \pm 0.55^{* * *}$ & $-4 \cdot 60 \pm 0 \cdot 88^{* * *}$ & $1.52 \pm 0.83$ n.s. \\
\hline $2 a$ & - & - & - & $-0.89 \pm 1.00$ n.s. \\
\hline $3 a$ & - & - & - & $-5 \cdot 70 \pm 1 \cdot 19 * * *$ \\
\hline$b$ & - & - & - & $-2.98 \pm 1.91$ n.s. \\
\hline $4 a$ & - & - & - & $-4 \cdot 73 \pm 1 \cdot 35^{* * * *}$ \\
\hline $\begin{array}{r}5 a \\
b\end{array}$ & $0.13 \pm 1.69$ n.s. & $\begin{array}{l}0.06 \pm 0.47 \text { n.s. } \\
3.73 \pm 0.80^{* * *}\end{array}$ & $\begin{array}{l}1.35 \pm 0.83 \text { n.s. } \\
2.66 \pm 1.43 \text { n.s. }\end{array}$ & $\begin{array}{r}-0.85 \pm 0.57 \text { n.s. } \\
0.47 \pm 1.41 \text { n.s. }\end{array}$ \\
\hline $\begin{array}{l}c \\
d\end{array}$ & $-0.85 \pm 8.22$ n.s. & $-6 \cdot 96 \pm 2 \cdot 08^{* * *}$ & $-10 \cdot 30 \pm 3 \cdot 73^{* *}$ & $-5 \cdot 14 \pm 2 \cdot 16^{*}$ \\
\hline
\end{tabular}

This is not surprising since only one out of seven comparisons of reciprocal family means, namely that of the $F_{1}$, was significant for either character in this season (tables 1, 3 and 4). A simple additive-dominance model of the reciprocal differences is, therefore, adequate within the errors of the family means of the 1956 experiment.

For final height in the remaining three experiments (table 8) there is more consistent evidence of a positive great-grandmaternal effect (test $1 b$ ) than of a negative grandmaternal effect (test 1a). This agrees with the earlier analysis in table 5. Although, in table 8 (tests $1 a$ and $1 b$ ) the significances are attributed to additive gene action, more complex causes involving interactions are not ruled out and are even suggested by the reversal in sign and magnitude. The tests for dominance and dominance interaction contributions to the maternal effect (tests $1 c$ and $1 d$ ) are not significant but they are consistently positive in sign. The non-significance of test $2 a$ suggests that neither paternal effects nor linked pairs of interacting genes are important in these data. Equally tests $3 a$ and $3 b$ appear to rule 
out significant contributions from trigenic interactions. As a result the significance of test $4 a$ which detects both trigenic interactions and interactions between maternal line and paternal contributions is marginally in favour of the presence of the latter. The presence of maternal line $\times$ paternal interactions is also consistent with the significance of test $5 c$ (1969, sowing 1) which could, however, also indicate the presence of maternal line $\times$ progeny genotype interactions. Since the inconsistency between the maternal and great-grandmaternal effects on the one hand and the grandmaternal effects on the other also suggest some form of interaction the minimum model would appear to require either a maternal line $\times$ paternal interaction or a maternal line $\times$ progeny genotype interaction.

The overall picture for flowering time is similar although the interactions appear to be more complex or stronger. Thus dominance and dominance interactions as well as additive gene action appear to be involved in the maternal line effects (tests $1 d, 1969$ ) and trigenic interactions in the contribution of the progeny genotype (test $3 a$ ). The evidence for either a maternal line $\times$ paternal interaction or of a maternal line $\times$ progeny genotype interaction is also stronger (tests $5 b, 5 c$ and $5 d$ ).

The 1970 sowing 2 experiment alone provides sufficient family means for an investigation of the adequacy of models of the complexity indicated by the tests in tables 8 and 9. Additive and dominance gene action and digenic and trigenic interactions appear to be necessary for the contribution of the progeny genotype along with additive, dominance and dominance interaction contributions of the maternal, grandmaternal and greatgrandmaternal genotypes which interact with either the progeny genotype or a paternal effect.

Models specifying all these contributions have been fitted to the 26 family means using weighted least-squares procedures. The consequences of including less likely components in the models such as those which specify the contributions of grandpaternal and great-grandpaternal effects, epistatic interactions of the maternal genotype and linkage of pairs of interacting genes in the progeny genotype have also been investigated. Having found a model which minimised the $\chi^{2}$ testing the goodness of fit of the observed and expected family means, parameters were progressively eliminated, starting with the least significant, until a model was obtained in which all remaining parameters were significant and the $\chi^{2}$ non-significant. By this procedure we arrive at a model which is the simplest possible in terms of the kinds of gene action and interactions specified and in terms of the number of parameters involved that is both adequate and includes only essential parameters. Estimates of the parameters of the models which meet these criteria for the two characters are given in table 10 . Because $[d]$ and $2[d m]$ and $[d]$ and $2[d p]$ are completely correlated over the 26 expectations they cannot be individually estimated and appear in this table as the sums of the pairs of parameters (see Jinks and Perkins, 1969).

Reference to table 10 shows that the simplest adequate models for final height and flowering time are essentially the same. Both contain contributions from the progeny genotype, the maternal line genotype and maternal line $\times$ paternal interactions. They differ only in the kinds of gene action and interaction involved within these three classes of contributions. Before discussing the models further it is important to know whether other, equally satisfactory models exist. This is a real possibility when a large number 
of parameters are involved many of which are correlated. Two of the most closely related sets of parameters are those which specify maternal line $x$ progeny genotype interactions and maternal line $x$ paternal interactions. We have already noted that these cannot be readily distinguished on any of the individual tests in tables 7,8 and 9. This is not surprising when one considers that the maternal line component is common to both and the paternal

TABLE 10

Estimates of the parameters of the adequate models for final height and flowering time and the tests of their goodness of fit

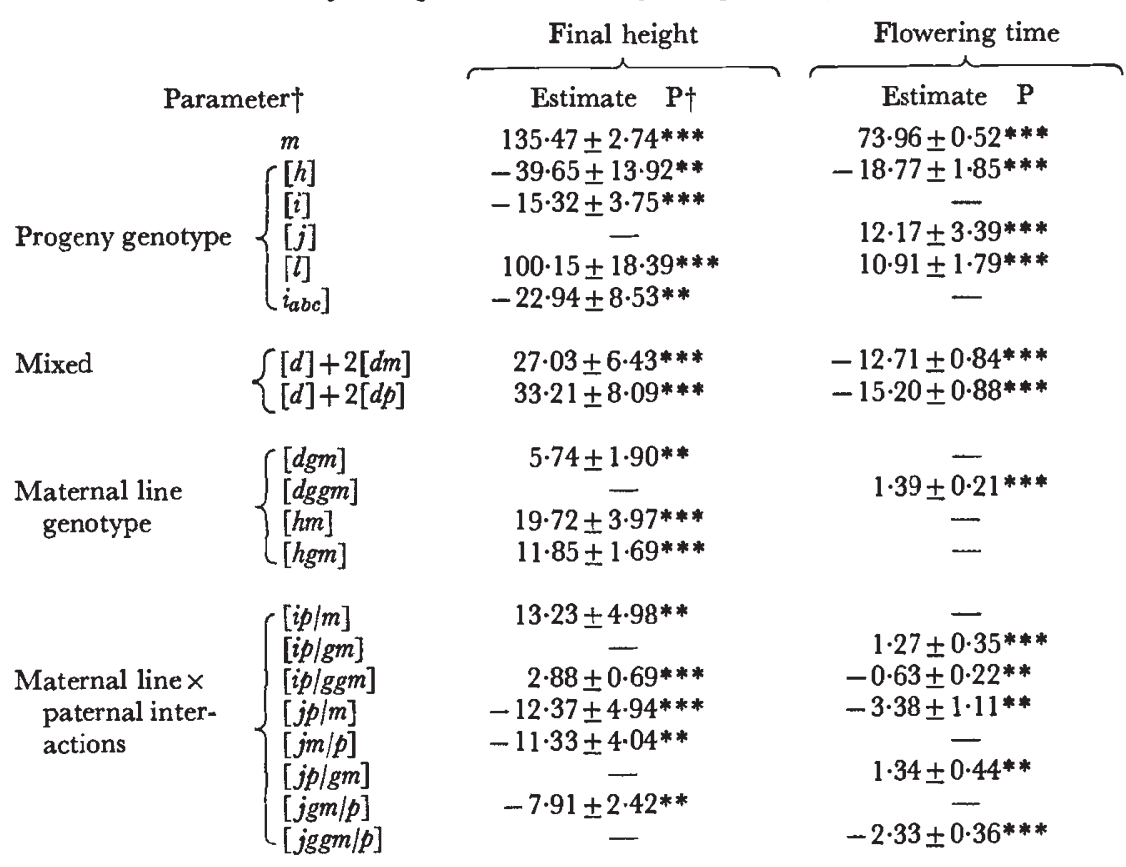

Goodness of fit $\chi^{2}$

14.58 for 11 d.f. n.s.

13.56 for 14 d.f. n.s.

$\dagger$ For definitions of parameters see section 3 and for probability levels see table 1 .

component also specifies half the parental contribution to the progeny genotype. It was anticipated, therefore, that models which substituted the progeny genotype interaction for the paternal interaction would come nearest to providing satisfactory alternatives. For final height this proved to be the case. This substitution alone of all the alternatives gave a model which met the earlier criteria of adequacy. It required, however, an additional three parameters. For flowering time, neither this substitution nor any other was a satisfactory alternative model. Thus only the paternal interaction model is adequate for both characters and it has been accepted as the better of the two models for this reason.

The contribution of the progeny genotype to the family means is much as expected from earlier analyses of the two characters. This is not so, however, for the contribution of the genotypes of the maternal line and the paternal parent. The signs of the original differences between the means of reciprocal families suggested maternal determination for final height and 
paternal determination for flowering time (tables 2, 3 and 4). The models (table 10) suggest that both maternal line and paternal contributions as well as interactions between them are involved in the determination of both characters - any difference between the characters being one of degree rather than of kind.

Although strict maternal determination still appears to be the commonest mode of cytoplasmic inheritance there are now a number of instances where both parents participate but to different extents (see Jinks, 1964, for a review). Given, therefore, that chromosomal gene products in the cytoplasm behave like cytoplasmic determinants in their transmission, there are clearly opportunities for the products of the genotypes of both the maternal and paternal parents to influence their progeny. Indeed, it may well be that where maternal determination has been reported on the basis of the direction of the difference between reciprocal $F_{1}$ families further breeding may reveal, as it appears to have done in the $\mathcal{N}$. rustica experiments, a lesser paternal contribution.

\section{Descriptions and explanations}

Three properties of the differences between the reciprocal $F_{1}$ families and of the further generations derived from them are largely responsible for the finding that the only satisfactory interpretation appears to be one involving maternal line effects, paternal effects and interactions between them. These are:

(i) the greater resemblance of reciprocal $F_{1}$ families to their paternal than to their maternal parent for flowering time;

(ii) the presence of significant reciprocal differences in families derived from the reciprocal $F_{1}$ families by selfing and back-crossing;

(iii) the greater significance of the reciprocal difference, and for final height the change in sign of this difference, in families of which the inbred varieties are great-grandparents compared with those of which they are grandparents.

Taken together, these properties and hence their interpretation are unique. The results of reciprocal crosses among inbred maize varieties recently reported by Garwood et al. (1970) are, however, very similar as far as they go. They found, for example, that for some characters, such as oil content, the reciprocal differences were often consistent with a maternal control while for others, such as plant and ear height, the reciprocal crosses showed a stronger resemblance to their paternal parent. Furthermore, the direction of the difference in oil content between the reciprocal $F_{1}$ families was reversed in the $F_{2}$ families derived from them. There is, therefore, a correspondence on the one hand between oil content in maize and final height in $\mathcal{N}$. rustica, and on the other, between plant and ear height in maize and flowering time in $\mathcal{N}$. rustica.

The comprehensiveness of the survey of possible models that preceeded the choice of the one presented as the best leaves little doubt that it provides a formally correct description of the $\mathcal{N}$. rustica data and presumably of the maize data also. The explanation of the underlying genetical control, however, may well involve factors which are not part of these analyses. Thus 
no explanation would be complete which failed to take into account the positive correlation between final height and flowering time which appears to be widespread in $\mathcal{N}$. rustica. Varieties 2 and 12 are unusual in this respect in that variety 12 is both the taller and the earlier flowering, hence these two varieties stand in reverse relationship to this general correlation. Nevertheless, in respect of the environmentally produced variation within these two inbred varieties and their $F_{1}$ and the environmentally and genetically produced variation in the segregating generations of this cross the more usual positive correlation is observed. It appears, therefore, that the general rule that anything which makes a plant or family taller also makes it flower later applies to these two varieties and the generations derived from crosses between them.

Maternal control of the reciprocal differences in this cross would have given families which are taller and earlier flowering with variety 12 as the mother compared with the reciprocal cross. That variety 12 as the mother produces families which are taller and later flowering than the reciprocal cross could, therefore, be explained in terms of the positive correlation between the two characters. Evidence that this correlation is operating among the reciprocal $F_{\mathbf{1}}$ families for the environmentally produced variation can be found at two levels. Within each reciprocal $F_{1}$ family within each of the 18 experiments there are positive regressions of flowering time on final height. These regressions are homogeneous over reciprocal families in each experiment but heterogeneous over experiments, the mean regression coefficient being $0 \cdot 19(\mathrm{P}<0.001)$. This mean value is not significantly different from the regression of the magnitude of the reciprocal difference for flowering time on that for final height over the eighteen experiments $(0 \cdot 22, \mathrm{P}<0 \cdot 001)$. Neither of these linear regressions, however, accounts for all the significant variation in flowering time and there are no indications that the variation unaccounted for is due to quadratic or higher order components of regression. We can use the significant linear regression to test the hypothesis that there would be no mean difference between reciprocal crosses for flowering time in the absence of such differences for final height. For a zero difference in final height the expected mean difference for flowering time is $2.64 \pm 1.39$ days. While this is positive and hence shows a residual paternal effect it is not convincingly significantly different from zero ( $P=$ $0 \cdot 10-0 \cdot 05)$. Thus all the reciprocal differences for flowering time apart from the random deviation from the linear regression appear to be accountable as the correlated consequences of the reciprocal differences for final height. It could also be argued that these random deviations result from the significant differences in the relationship between the two characters within different experiments which were noted earlier. It is conceivable, therefore, that all the reciprocal differences for flowering time and hence all the resemblance to the paternal parent of the cross for this character could be explained as a correlated response of the maternal effect on final height. Since we are arguing from correlations it can, of course, equally be argued that the maternal effect on final height can be explained as a correlated response to the paternal effect on flowering time. The relative frequencies of proven cases of maternal as opposed to paternal effects is, however, overwhelmingly against this alternative. While, therefore, the models presented in section 3 (iii) of this paper give a formally correct description of the inheritance of flowering time and final height in the cross between varieties 
2 and 12 and provide the basis for making predictions it seems likely that, if allowance could be made for the correlations between the two characters, nothing of the reciprocal differences for flowering time, which are difficult to account for in conventional terms, would remain to be explained. Clearly, if the reciprocal differences for flowering time merely reflect those for final height this is a further reason for preferring the only model, namely, that involving maternal line effects and maternal line $\times$ paternal interactions, that equally and satisfactorily describes both characters.

\section{Summary}

1. The means of the reciprocal $F_{1}$ families of the cross between varieties 2 and 12 of Nicotiana rustica differ significantly for final height and flowering time in the majority of the 18 experiments in which they have been compared.

2. These differences persist at reduced levels for at least two further generations of selfing and back-crossing of the original reciprocal $F_{1}$ families although for final height they are more pronounced after two further generations than after one.

3. The signs of the differences between reciprocal family means relative to those of the differences between the parental varieties in the same experiment suggest a maternal effect on final height and a paternal effect on flowering time in most experiments.

4. On the assumption that the reciprocal differences arise from the delayed action of maternal or paternal genes, models have been constructed which specify the contributions of maternal, grandmaternal, greatgrandmaternal and paternal genotypes, maternal line $\times$ progeny genotype interactions and maternal line $\times$ paternal interactions to the means of the 26 kinds of families available in the most extensive of the 18 experiments.

5. On the basis of these specifications tests have been devised which detect any deviation from a model accounting for the reciprocal differences involving only the additive and dominance action of maternal genes.

6. A combination of these tests and model fitting by weighted least squares procedures has led to the elucidation of the simplest model which will adequately account for both the final height and flowering time data.

7. For both characters this model includes contributions from the progeny genotype, maternal line genotype, paternal genotype and interactions of the maternal line and paternal contributions.

8. Evidence and arguments are presented that suggest that the reciprocal differences for flowering time, which lead to a greater resemblance to the paternal than to the maternal parent of a cross, arise as a positively correlated response to the reciprocal differences for final height.

Acknowledgments.-Part of these analyses were carried out while R. S. G. was supported by a postgraduate fellowship in plant breeding of the National Seed Development Organisation Ltd. and the British Association of Plant Breeders.

\section{REFERENCES}

BARNES, B. w. 1968. Maternal control of heterosis for yield in Drosophila melanogaster. Heredity, $23,563-572$.

BEDDOWS, A. R., BREESE, E. L., AND LEWIS, B. 1962. The genetic assessment of heterozygous breeding material by means of a diallel cross. I. Description of parents, self- and cross-fertility and early seedling vigour. Heredity, 17, 501-512. 
BHAT, B. K., AND DHAWAN, N. L. 1971. The role of cytoplasm in the manifestation of quantitative characters of maize. Genetica, 42, 165-174.

FULKER, D. W. 1970. Maternal buffering of rodent genotypic responses to stress. A complex genotype-environment interaction. Behav. Genetics, 1, 119-124.

GARWOOD, D. L., WEBER, EVELYN, J., LAMBERT, R. J., AND ALEXANDER, D. E. 1970. Effect of different cytoplasms on oil, fatty acids, plant height and ear height in maize (Zea mays L.). Crop Sci., 10, 39-41.

HAY, D. A. 1972 . Genetical and maternal determinants of the activity and preening behaviour of Drosophila melanogaster reared in different environments. Heredity, 28, 311336.

HAYWARD, M. D., AND BREESE, E. L. 1968. The genetic organisation of natural populations of Lolium perenne L. III. Productivity. Heredity, 23, 357-368.

JINKS, J. L. 1956. The $F_{2}$ and the backcross generations from a set of diallel crosses. Heredity, $10,1-30$

JINKs, J. L. 1964. Extrachromosomal Inheritance. New Jersey: Prentice-Hall Inc.

JINKs, J. L., AND JONEs, R. M. 1958. Estimation of the components of heterosis. Genetics, 43, 223-234.

JINKS, J. L., AND PERKLNS, JRAN M. 1969. The detection of linked epistatic genes for a metrical trait. Heredity, 24, 465-475.

JINKs, J. L., AND PERKINS, JEAN M. 1970. A general method for the detection of additive, dominance and epistatic components of variation. III. $F_{2}$ and backcross populations. Heredity, 25, 419-429.

MATHER, K., AND JINKs, J. L. 1971. Biometrical Genetics: the Study of Continuous Variation, 2nd ed. London: Chapman \& Hall. 